\title{
Media Policies for Egyptian Television According to the Constitutional Clause for Sport
}

\author{
Kawthar El-Said El-Mogy ${ }^{1}$, Mahmoud El-Sayed El-Asbah ${ }^{2}$, Dina Kamal Mahmoud ${ }^{3}$ \\ ${ }^{1}$ Professor, Faculty of Physical Education for Boys, Helwan University, Egypt \\ ${ }^{2}$ Assistant Professor, Faculty of Physical Education, Port-Said University, Egypt \\ ${ }^{3}$ Assistant Professor, Faculty of Physical Education for Girls, Helwan University, Egypt
}

\begin{abstract}
Egyptian TV sports programs are representing the media policies of the state, and must work in order to implement the new Constitution of 2014 clauses. The Purpose of this study was to Identify the nature of media policies to Egyptian television programs in accordance with the requirements of the new Constitution of 2014 clauses, and Determine the features of the proposed media plan for TV sports Egyptian to maximize sports practice.
\end{abstract}

Researchers used the survey method, Total sample was (1408) person, including three variety categories, The first category is the officials and workers in the Nile Sport Channel $(n=65)$, Second category; Specialists in Sports and Physical Education $(n=143)$, and the third category is the public beneficiary $(n=1200)$.

Methods used of data collection is the Content analysis In the Nile Sport channel programs In addition to the personal interview and a questionnaire.

The study revealed significant results for:

The media policies of TV sports Egypt (Nile Sport Channel) has seen absence of the application of balanced regarding the constitutional text of the sport accordance with clause (84) of the Constitution of 2014 about the role of the official sports TV to take the necessary measures to promote the practice of physical activity For the various categories.

Objectives of sports programs in official TV has not changed even keep pace with the changes of constitutional provision for sport.

There is a shortage in the Nile Sport channel to provide Firmware with academics, and specialists in the field of sports In order to develop sport and encourage the practice for all categories

In Conclusion, the present study determine the most important controls proposed media plan of Egyptian television sports to maximize the Practice to all categories in accordance the clause of the constitutional 2014 for sport, with the presentation of the important aspects of media policies needed to achieve these controls.

\section{Introduction}

$I^{n}$ $n$ the text of the Egyptian constitution 2014 article (84) that "the practice Sports be right for everyone, and must be on the state and society that the discovery of talented athletes and care, and to take the necessary measures to encourage the practice of sports ", this article describes the role of the Egyptian state television who specializes in supporting sports, sports activities and to clarify to the public, and the purpose is to spread the practice of sports development and increase practitioners base culture, and then work to maximize sports practice to all segments of society qualitative of children, elderly, women, disabled and young people, and then the development of the Egyptian sports; however, the official sports media of the state away from programs that achieve this goal, but it came down to the targets do not check this public benefit of Sport for the citizen and head toward foreign periodicals and football games competitive and display problems, these events only, And then discusses these study besides media policies in the Egyptian state TV (Nile Sport), and the extent of its commitment to the articles of the Constitution, and plans varied sports programs for the various categories that are based on these policies. 
Sports media plays a vital role in the progress of peoples or decline, and measured the progress of nations in the sport according to the offers of the media athlete distinct and varied in different media, and must be dealt with to provide news and sports accurate information objectively and impartially, as the public provides the facts that will help them to understand what is going on around them and form good opinions on sports issues, in addition to role in spreading awareness of sports and encourage sports practice for all segments of society (El hady, 2012).

Television is one of the most powerful media to deliver news and dissemination of cultures and bring community awareness because of its important role in the composition of impressions and form trends, making it enjoys a super attractive without other media (Shuaibi, 2004). As it leads a clear role in the composition of the mental image of the members of both the state trends and policy institutions and events that prevailed. It affects the way in which people perceive issues, and the way they think, and in their behavior towards their world in which they live (Turkistani, 2004). It also offers viewers the knowledge, ideas and experience in integrated scenes based on the live image expressive associated sound indicative of the depth of feelings and the significance of events and facts. (Moawad, 2000).

Content provided by the TV is of great importance and must keep pace with developments in society and political systems (Jabri, 2006 ). The critics agree that television has a peak efficiency when media direct transport to events, conferences and other activities locally or around the world, and that makes TV programs, a major source for the public on the different classes and cultures. (Haidari, 2005) In addition to the TV directed to many other societies and cultures, the effect of channels and programs on those cultures will be clear in making the local culture, a reflection of the combination of social and economic infrastructure in the community and this cultural change will result in a change in the social structure (Jacob, 2012). Field studies have shown that the viewers believe validity of the televised events than read it in print or broadcast, in the United States report mentions the Washington Post published on 4/4/2008 that "almost two-thirds of Americans get news from TV (Annabaa, 2007).

On the other hand media policies that reflect "the principles and criteria Activity State Control in one area, towards some processes, organization, management, supervision, evaluation, and the harmonization of mass communication to him In order to achieve the best possible results in the social context of political, social and economic model in the present state. And these policies media designed to optimize use of the media available in the state, and should not be a mere declaration in nonspecific targets, but must reflect the specific objectives seeking to be achieved TV media service of the State (Musalami, 2003)

Based on that, this study aimed identify the nature of media policies to Egyptian television programs and whether conform with the new constitutional text of the sport, and what are the controls proposed media plan for the Egyptian TV to maximize sports practice, according to the Constitution of 2014

\section{Material and Methods}

\section{Descriptive Approach (Survey Style)}

Population: includes Nile Sport channel; it is only official channel in the field of sports in the Egyptian TV, and officials, and those who made the communicative transactions, in the channel, and target audience of viewers.

Sample: chosen purposively stratified way from the research community, and its officials and employees in the category of the channel and reached (65) person, and the category of specialists in physical education and sport and amounted to (143) person, while the category of beneficiaries reached (1200) person.

\section{Data collection method :}

(A) Personal interview : Used a personal interview with members of the research community, which includes (officials and workers in the Nile Sport Channel), and a number of the beneficiary of the public TV viewers of different qualitative categories.

(B) Analyzing the content of Nile Sport channel programs: Researchers analyzed the content that is broadcast through the Nile Sport channel and its content of programs and section, and the validity of this content to maximize community sports practice, so that it can develop a media plan Egyptian television consistent with the constitutional text of the sport in order to promote sports practice.

(C) Questionnaire: the questionnaire used as a means for scientific data collection to identify the impact of the Egyptian TV programs on the practice of qualitative categories for sports activities, where it was found on references and studies related, it were displayed a number of themes and phrases on the experts to determine their suitability. 
Pilot study: Applied to the (142) person from outside the basic sample, and have the same characteristics and conditions, were selected stratified random way. The following table shows the sample descriptions of pilot study relative to the basic study.

Table (1)

Descriptions of pilot study relative to the basic study

\begin{tabular}{|c|c|c|c|c|}
\hline No & Research sample categories & basic study & pilot study & Percentage \\
\hline 1 & officials and employees in the channel & 65 & 7 & $10.77 \%$ \\
\hline 2 & specialists in physical education and sport & 143 & 15 & $10.49 \%$ \\
\hline 3 & public beneficiary from qualitative categories & 1200 & 120 & $10.00 \%$ \\
\hline & Total & 1408 & 142 & $10.08 \%$ \\
\hline
\end{tabular}

Table shows the percentage of representation the pilot study relative to the basic study, it reached (10.08\%), and through the pilot study were conducted scientific transactions.

\section{Scientific transactions:}

\section{A- Validity:}

1) Validity of experts; The questionnaire was given to (7) experts (Attached 1) for their opinion on the axles study (Attached 2), and phrases (Attached 3).The approval rate Experts reached $(100 \%)$ of the axes And ranged from $(85.71 \%$ to $100 \%)$ of the phrases.

2) Validity of Internal Consistency; Questionnaire was applied to the pilot sample (142) Person, through correlation between each statement and the total axis belong to him. All came significance and ranged between (0.439*: 0.869) and thus become final phrases (20) (Attached3), and have been calculating the correlation between the sum of each axis and the total of the questionnaire. All came significance and ranged between (0.798*: 0.901*). (Attached4)
B- Reliability: Split half has been applied Using alpha coefficient for Reliability according to the statistical formula (Kuder \& Richardson), The value of "Alpha" ranged between $\left(0.781^{*}, 0.859^{*}\right)$. (Attached5), confirms that the questionnaire to an acceptable degree of reliability

Basic study: It was applied in its final form (attached 6) from $14 / 09 / 2014$ to $26 / 10 / 2014$ on the study sample, its consisted of (1408) Person.

Statistical method: SPSS, descriptive statistical, percentages, Chi- Square $(\chi 2)$

\section{Results and Discussion}

\section{A) Content analysis of Egyptian TV programs (Nile Sport Channel):}

To discuss and analyze the content of sports programs for the channel Nile Sport the researchers based on the following table, which shows the name of the program and his time-generated content in it. 
Kawthar El-Mogy et. al.

Table (2)

Content analysis of Egyptian TV programs (Nile Sport Channel)

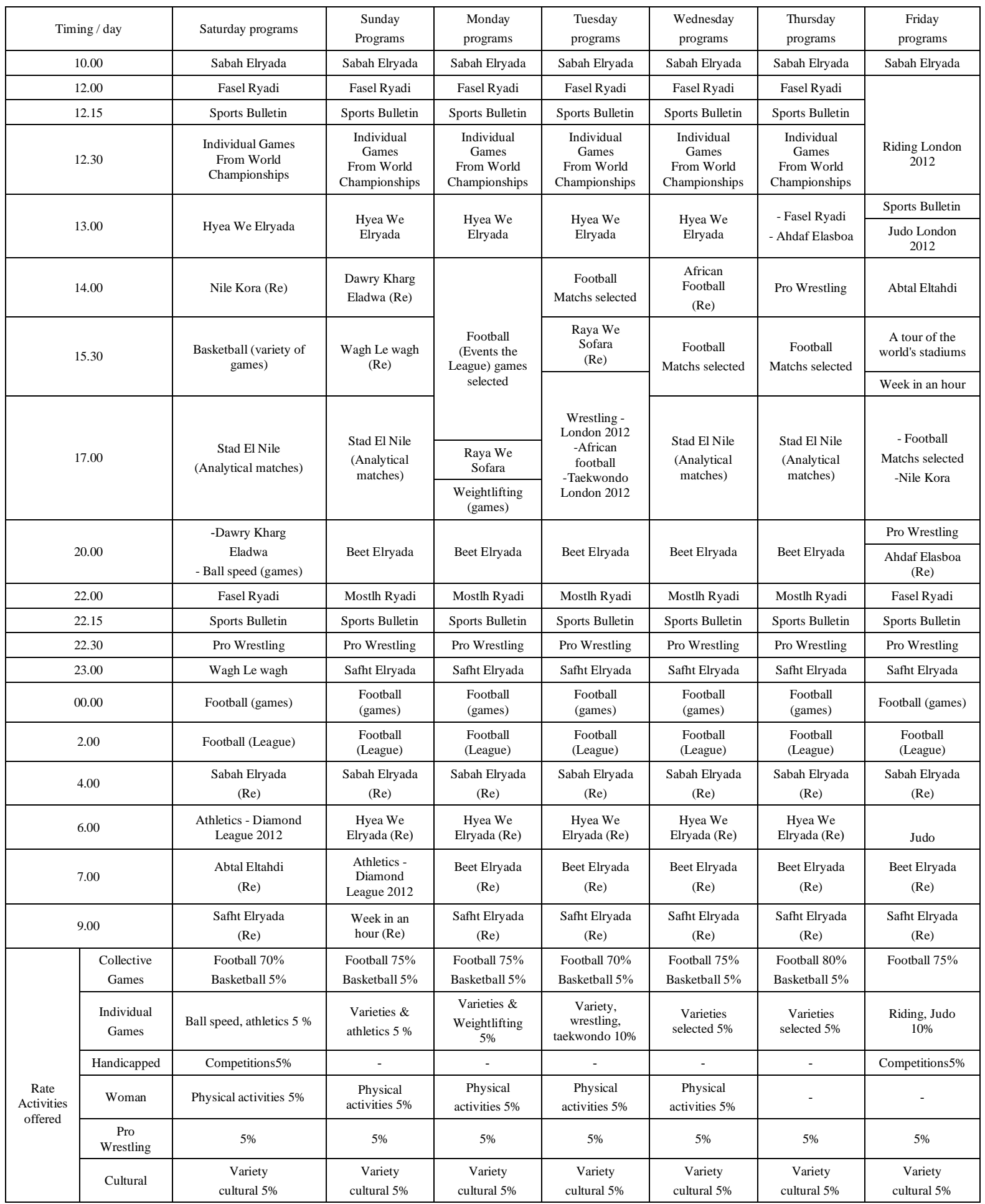


Table (2) shows weekly sports programs that Provided by the Egyptian Nile TV through Sport sports channel. It is clear from the follow-up of these programs great attention to competitive football as a basic material for its content and substance, the proportion of offer football programs ranged from $(70 \%$ to $80 \%)$ during the daily supply periods.

The table also shows the proportion of sports activities provided in individual games, which ranged between $(5 \%$ and $0.10 \%$ ) during the daily supply periods in some games like Speed games, athletics, weightlifting, wrestling, judo, and a number of individual games selected and varied, While ranged in the sports activities for people with disabilities between $(0 \%$ to $5 \%)$ during the daily supply periods, which were presented in the form of competitive sport,

As well as physical activities that targeting women through the program presented "she and sport" ranged between $(0 \%$ to $5 \%)$ during the daily supply periods, which were presented in the form of training and information of interest to this category, while professional wrestling has achieved fixed ratio of $(5 \%)$ during the daily supply periods throughout the week, and also got cultural entertainment and section European League News at a fixed ratio of $(5 \%)$ during the daily supply intervals throughout the week.

These results are consistent with the study Mateusz and Scott (2014) that there is a clear interest in sports TV programs in the sport of football, and that there are a huge number of fans of European sport in the Arab societies, and that this affects the content of local programs.

As well as consistent with the study (El Asbah, 2013) that the sports programs offered by the media need to replanning in a scientific and qualitative in order to be commensurate with the performance of specialists and the needs of the fans, and the sports media lacks scientific criteria for the selection of professionals in the Egyptian media sport. And study (Scott et al., 2013) which shows that sports programs via satellite transmission channels are dealing with the concept of competitive sport perspective to strengthen the economic aspects, without sufficient attention to the concept richer social and cultural aspect, and this does not meet the needs of some types of fans.

The researchers comment that these results shows an application unbalanced for constitutional clause for sport about the role of state institutions to take the necessary measures to promote sports practice as a right for all segments of society (children, youth, elderly, women, the disabled, ..) whereas is State TV, who specializes in sports, "Nile Sport" most prominent of these means; however, the attention goes towards games and competitions Egyptian league and football in general, both at the local scale or European Leagues, due researchers to the globalization of the sport and global trend towards investment, which diminishes with citizen interest and need in physical activity and leisure time in a constructive way, which shows the need for the formulation of a media plan to guide the official TV.

Results also consistent with (Mahmoud and Ali, 2011) that "the media should be given to the deployment of the concept of sports for all towards the community is dealing with the sport as a need for each core of its members, the media must working to amend the beliefs of interest in various forms of sport, State should be provides financial resources to complete the infrastructure facilities, and the preparation of a private women's sports programs. As well study of (Elgioshy and Radi, 2005) also shows that Egyptian sports influenced by political changes, has proved to all, it must balance the media organization to support forms of the sport, even materialized Interest to the public beneficiary. And the labor market in the sports media, not only limited to the specialization Media, but based on criteria other than quality standards, and therefore should be the goal is to serve the citizens and abandonment of personal interests.

B) Present and discuss the results of questionnaire:

1. Media policies related to the objectives of the

Egyptian sports TV programs : 
Table (3)

Percentage of sample opinions on media policies Related to the objectives of the Egyptian sports TV programs according to needs of public $(n=1408)$

\begin{tabular}{|c|c|c|c|c|c|c|c|c|}
\hline $\mathrm{N}$ & Statement & yes & $\begin{array}{c}\text { To } \\
\text { some } \\
\text { extent }\end{array}$ & No & $\begin{array}{l}\text { Estimated } \\
\text { grades }\end{array}$ & $\%$ & $(\chi 2)$ & Arrangement \\
\hline 1 & TV sports programs aimed only entertainment & 224 & 531 & 653 & 2387 & 56.51 & $208.2^{*}$ & 2 \\
\hline 2 & $\begin{array}{l}\text { TV interested to take the necessary measures to } \\
\text { encourage practice of sports }\end{array}$ & 136 & 316 & 956 & 1996 & 47.25 & $791.4^{*}$ & 8 \\
\hline 3 & $\begin{array}{l}\mathrm{TV} \text { affect the desired role in the dissemination of } \\
\text { culture and promote qualitative community categories } \\
\text { on ways to practice sports }\end{array}$ & 146 & 613 & 759 & 2423 & 57.36 & $335.5^{*}$ & 1 \\
\hline 4 & $\begin{array}{l}\text { Sports programs provided interested in development of } \\
\text { sports awareness for all ages of both sexes and provide } \\
\text { models for that }\end{array}$ & 122 & 416 & 870 & 2068 & 48.96 & $605.1 *$ & 6 \\
\hline 5 & $\begin{array}{l}\text { TV sports programs objectives are changing to keep } \\
\text { pace with societal change and the constitutional clause }\end{array}$ & 82 & 397 & 929 & 1969 & 46.61 & $781.0^{*}$ & 9 \\
\hline 6 & $\begin{array}{l}\text { Sports program objectives are varied to include all the } \\
\text { needs of public. }\end{array}$ & 93 & 422 & 893 & 2016 & 47.73 & $688.9^{*}$ & 7 \\
\hline 7 & $\begin{array}{l}\text { Sports programs offered objectives Consistent with the } \\
\text { requirements of every age and stage of their changes, } \\
\text { And what needs for Sports practice }\end{array}$ & 143 & 408 & 857 & 2102 & 49.76 & $555.1^{*}$ & 4 \\
\hline 8 & $\begin{array}{l}\text { TV aims to achieve the principle of democratic } \\
\text { communication (public participation) in program } \\
\text { planning and implementation }\end{array}$ & 187 & 470 & 751 & 2252 & 53.31 & $338.8^{*}$ & 3 \\
\hline 9 & $\begin{array}{l}\text { Those who communication have } \\
\text { under pressure, that is influence about choice of the } \\
\text { societal benefit programs }\end{array}$ & 65 & 563 & 780 & 2101 & 49.74 & $572.6^{*}$ & 5 \\
\hline
\end{tabular}

* Value $\chi 2$ Tabulated at $0.05=5.99$

The table shows the percentages of the responses to the study sample phrases axis "of media policies related to the objectives of the Egyptian sports TV programs according to needs of public ", which ranged between (46.61\% to $57.36 \%)$. As shown the existence of differences Statistically significant at the level of significance $(0.05)$ between iterations seen and projected in all phrases in favor of responding (no), and the value of calculated $\chi 2$ ranged between $\left(208.2^{*}\right.$ to $\left.791.4^{*}\right)$ and the phrase "3" reaching on a limited percentage although ranked first, and the results showed in the latter arrangement phrase number "5".

The researchers commented that the media policies official television sports; have been affected by a number of economic and trade variables at the expense of aspects of educational media aimed, not only limited to the Egyptian society, but extended to a number of developing countries and possibly at the level of specialized and academic organizations and the media. Media policies now become one of the requirements of the times as part of the comprehensive plans of any state, as in Western countries, there is interest in media planning in the broadcast media and content sectors targeted to specific categories, and production engineering and external media, which is based on the basis of the overall strategy of the State in accordance with the main legislation , and therefore It requires a comprehensive national media policy including the sub-branch policies for each way of the media in addition to the various communication activities, and combine this information policies to keep pace with societal change and the constitutional clause.

These results are consistent with the study of (Zahaf, 2010) that sports programs Algerian TV is inadequate and does not meet the need of the public, in return how much the number of sports activities on the sports arena which affects the nature of the media message that sports programs offered by community and usefulness, In addition to the shortage of possibilities for the implementation of sports programs and the absence of a functional structure to divide the work between those in charge of sports television programs which gives rise pressure at work to create sports programs with an outstanding level. 
While the results of (El Asbah,2010) shown that there are internal and external pressure factors influence the choice of the nature of the programs that provide for fans,, among these factors; budget allocated for publication, devoted to the preparation of human resources, advertising, owner intervention in directing the media policy of the channel, trends in public opinion, laws governing the media, national Security, opinions pundits. This also consistent

Table (4)

Percentage of sample opinions on media policies Related to

the nature of the Egyptian sports TV programs according to needs of public $(n=1408)$

\begin{tabular}{|c|c|c|c|c|c|c|c|c|}
\hline $\mathrm{N}$ & Statement & yes & $\begin{array}{c}\text { To } \\
\text { some } \\
\text { extent }\end{array}$ & No & $\begin{array}{l}\text { Estimated } \\
\text { grades }\end{array}$ & $\%$ & $(\chi 2)$ & Arrangement \\
\hline 10 & $\begin{array}{l}\text { Egyptian TV offers programs take into account the } \\
\text { needs of males and females during periods display } \\
\text { appropriate timing. }\end{array}$ & 423 & 389 & 596 & 2643 & 62.57 & $52.5^{*}$ & 4 \\
\hline 11 & $\begin{array}{l}\text { Egyptian TV balancing in the programs presentation } \\
\text { between the various sports activities. }\end{array}$ & 97 & 412 & 899 & 2014 & 47.68 & $695.7 *$ & 10 \\
\hline 12 & $\begin{array}{l}\text { Sports information Egyptian TV offers an interesting } \\
\text { way and keep abreast of technical change. }\end{array}$ & 474 & 425 & 509 & 2781 & 65.84 & $7.5^{*}$ & 3 \\
\hline 13 & $\begin{array}{l}\text { Presenters sports programs using professional and } \\
\text { technical methods in the delivery of information. }\end{array}$ & 403 & 378 & 627 & 2592 & 61.36 & $80.1^{*}$ & 5 \\
\hline 14 & $\begin{array}{l}\mathrm{TV} \text { offers a fixed section for the development of sports } \\
\text { and sports practice with field specialists. }\end{array}$ & 80 & 395 & 933 & 1963 & 46.47 & $636.6^{*}$ & 11 \\
\hline 15 & Exploiting space of time rebroadcast old games & 873 & 261 & 274 & 3415 & 80.85 & $520.9 *$ & 1 \\
\hline 16 & $\begin{array}{l}\text { Are presented and provide TV programs in the context } \\
\text { of professional ethics. }\end{array}$ & 204 & 549 & 655 & 2365 & 55.99 & 236.9 & 6 \\
\hline 17 & $\begin{array}{l}\text { Media content achieve appropriate communication with } \\
\text { the needs of internal and external fans. }\end{array}$ & 124 & 419 & 865 & 2075 & 49.12 & $593.1 *$ & 9 \\
\hline 18 & $\begin{array}{l}\text { Achieve programs cultural needs of different groups } \\
\text { and social strata such as programs for children, youth, } \\
\text { adults, women and disabled }\end{array}$ & 185 & 477 & 746 & 2255 & 53.39 & $335.4 *$ & 7 \\
\hline 19 & $\begin{array}{l}\text { TV services with sufficient about credibility from the } \\
\text { point of view of the public. }\end{array}$ & 166 & 389 & 853 & 2129 & 50.40 & $523.4 *$ & 8 \\
\hline 20 & $\begin{array}{l}\text { TV programs have reached the levels required for the } \\
\text { technical needs of the fans. }\end{array}$ & 692 & 352 & 364 & 3144 & 74.43 & $158.6^{*}$ & 2 \\
\hline
\end{tabular}

* Value $\chi 2$ Tabulated at $0.05=5.99$

The table shows the percentages of the responses to the study sample phrases axis "of media policies related to the nature of the Egyptian sports TV programs according to needs of public ", which ranged between $(46.47 \%$ to $80.85 \%$ ). As shown the existence of differences statistically significant at the level of significance (0.05) between iterations seen and projected in all phrases in favor of responding (no), and the value of calculated $\chi^{2}$ ranged between $\left(7.5^{*}\right.$ to $\left.695.7^{*}\right)$ and the phrase "15" reaching a high percentage of opinions the sample in the first place, and the results showed in the latter arrangement phrase number "14". with (Henning, 2010) that must be varied sports programs objectives. to include all the needs of Fans without focusing on the transfer of a particular sport excessively where that affects the reaction public and the need for community sports.

\section{Media policies related to the nature of the Egyptian sports TV programs:}


with field experts from the academic and practical sides has big return to the development of the Egyptian sports, starting from the family, ending with the professional role which represents a clear media policy for the application of the constitutional clause of the sport.

These results are consistent with the study of (Young, 1994) the evolution of the production and distribution of information technology in multiple TV channel, has led to greater attention to the different ages for the fans sports programs based upon, must provide information and interesting way to keep up with this technological change.

It also confirms the study of (Christopher et al., 2013) there is a gap between attitudes and aspirations of the general public, and what they offer some satellite broadcasting channels, and that there are some developing countries still suffers from presence of structures and systems doesn't meet the needs of their communities in a comprehensive manner, due to poor training and rehabilitation programs for workers to use professional techniques in the delivery of information which confirms the absence of the practical application of the constitutional clause of the sport.

While confirming results of (El Asbah, 2013) that technical and administrative performance development in Egyptian sports media industry and suitability to the needs of the fans requires the need to amend the regulations and legislation, which rules transfer process sporting events even TV is committed to the balance in the provision of programs between the various sports activities.

\section{Conclusions}

According to questions, and procedures research were extracted:

\section{A) Content analysis of Egyptian TV programs (Nile Sport Channel):}

- Percentage of providing competitive football programs ranging between ( $70 \%$ to $80 \%$ ) during the daily supply periods, while ranged between $(5 \%$ and $10 \%)$ in individual games, $(0 \%$ to $5 \%)$ in competitive sports activities for people with disabilities, $(0 \%$ to $5 \%)$ in physical activities targeting women, while got professional wrestling on a fixed rate of $(5 \%)$, as well as cult1ural got miscellany and section News of European League at a fixed ratio of (5\%) during the daily supply intervals throughout the week.

- The absence of a balanced application of the constitutional clause in accordance with Article 84 of the Constitution of 2014 about the role of state TV to take the necessary measures to encourage the practice of forms of physical activity for different categories.

\section{B) Media policies related to the objectives of the Egyptian sports TV programs:}

- Sports program objectives have not changed TV to fit with the constitutional clause for sport, according to the requirements of Article 84 of the Constitution of 2014.

- There is a lack of necessary measures by the TV to encourage sports practice to include the specific needs of the fans

- Sports programs offered targets don't adequately cover all ages and changes the requirements, and what need from sporting activity.

\section{c) Media policies related to the nature of the Egyptian sports TV programs:}

- There is a clear default on state television programs for providing fixed section for the development of sport and sports practice with domain specialists academics.

- Exploit the spaces of time in the rebroadcast old games.

- State TV Sports doesn't balance in the provision of programs between the various sports activities.

\section{Recommendations}

1- Taking controls proposed media plan Egyptian television to maximize sports practice according to the Constitution of 2014.

2- The proposal to establish the Supreme Council to manage the affairs of sports media a mechanism for the implementation of the media plan.

3- Must be on the official TV reformulation of goals to keep pace with the constitutional clause for sport In accordance with the requirements of Article 84 of the Constitution of 2014.

4- Develop the necessary measures for TV to encourage practice of sports to include the specific needs of the fans and the requirements of different ages and changes.

5- Inclusion of fixed section for the development of sports practice with specialists academics domain Sports and allocated enough time while minimizing the re-broadcast of old games.

6- To be a obligation regulations of the Organization for Media Sports principle in practice. 
7- Put the needs of the public in an advanced position commensurate with what is displayed.

8- Develop a map of sports programs covering all sporting events and practices, which are working in coordination with the government and private sectors to limit the control of the sports media institutions owners and hiring experts sports media specialists.

9- Provide technological techniques for the production and distribution of information to gain access to the global level

10- Adaptation human resources required for various operations of preparation and presentation.

\section{References}

1- Annabaa Informatics - Recent findings, 2007. Available at: http://www.annabaa.org/nbanews/62/491.htm accessed on 01.06 .2014

2- Christopher G; Greg G; Nick S.(2013): Understanding spectator expectations: an analysis of niche sports, International Journal of Sport management and Marketing (IJSMM). Vol. 13. No, 3/4.

3- El Asbah, M. E. (2010): Affecting Factors in Egyptian Sporting Media System, World Journal of Sport Sciences 3 (S): 219-229.

4- El Asbah ,M. E.(2013): Censorship legislation for Egyptian Sports Media And the Perspective of Western Society (Comparative Study). Sinai Journal of Sport Sciences (SJSS), 176- 189

5- Elgioshy, A. K., Radi, B. A.(2005): Application Requirements of TQM as an input for the development of the sports sector for all the Ministry of Youth. Journal of Menoufia University of Physical Education and Sports Vol. 1. 149-182.

6- El hady, I. (2012): Sports media educator, Dar Elktab Elhadeth, Cairo.

7- El-Jabri, A. (2006): news techniques in Arab satellite channels (Abu Dhabi satellite model) study - Ammon for Studies and Publishing. Oman. P. 53
8- Haidari, A. (2005): Picture and Television: construct meaning and content industry. Dar Elwasat Publications. Bahrain. p 45

9- Henning, E.( 2010): Bodily Democracy Towards a Philosophy of Sport for All, Routledge.pp 312.

10- Jacob, T. (2012): media techniques. Dar safhat Publications. Damascus

11- Mahmoud M. A., Ali H. F.(2011): Sports for all in the Arab Republic of Egypt between reality and ambition. Scientific journal Science of Physical Education and Sports. Vol 16.211- 260

12- Mateusz J, Scott T.(2014): Television Viewer ship of Out-of-Market Games in League Markets: Traditional Demand Shifters and Local Team Influence, Journal of Sport Management (JSM). Vol 28. Issue 1.

13- Moawad, M. (2000): television work Arts, 2nd Edition, Dar elfekr El-arabi, Cairo, p. 9.

14- Musalmi, I. A. (2003): the media legislation critical reading of the constitutional and legal foundations of that performance and media control, Dar El-fkr Publications. Cairo.

15- Scott T, Steven S, Carla A S.(2013): Determinants of Pay-Per-View Broadcast Viewer ship in Sports: The Case of the Ultimate Fighting Championship. Journal of Sport Management (JSM). Vol27. Issue 1.

16- Shuaibi, A.(2004): the role of the media between education and entertainment, El ofuk library, Kuwait. p.23

17- Turkistani, A. A. (2014): psychology of influence and persuasion through television, Saudi Association for Media and Communication, Riyadh. pp. 45

18- Young E.S. (1994); "Elopement Of Multi. Channel TV, And TV News Jawing: Across Sectional Analysis Of TV News", Journal of Media research, Vol. 56-10 A.6

19- Zahaf, M.(2010): An analytical study of sports television programs Algerian to strengthen the field of sports for all: Journal The University of Anbar Sport and Physical Education.Vol 1 Issue 2, 112-130 
